\title{
Women's Spending Behaviour is Menstrual-Cycle Sensitive
}

\author{
Short title: Spending is Menstrual-Cycle Sensitive
}

IN PRESS 2010 PERSONALITY AND INDIVIDUAL DIFFERENCES

\author{
Professor Karen J Pine* \\ Professor Ben (C) Fletcher
}

\author{
School of Psychology \\ University of Hertfordshire \\ College Lane \\ Hatfield \\ AL10 9AB
}

${ }^{*}$ corresponding author: email k.j.pine@herts.ac.uk

Telephone: (0) 1707284000

Fax: (0) 1707285073 


\title{
Women's Spending Behaviour is Menstrual-Cycle Sensitive
}

\begin{abstract}
When considering why women are more prone to money pathologies than men the influence of ovarian hormones cannot be ruled out. The phases of the menstrual cycle are known to have a range of behavioural, psychological and physical correlates. It is well documented, for example, that women are more rational and controlled post-ovulation, but experience a rise in impulsive behaviour, anxiety and irritability during the pre-menstrual (or luteal) phase. At ovulation, or peak fertility, it has been shown that women adapt their dress style to impress men - known as the ornamentation effect. However, to date the role of fluctuating ovarian hormones on female economic behaviour has been largely ignored. This article reports the findings from a survey of 443 females, aged $18-50$, reporting their spending in the previous seven days and their menstrual cycle phase, follicular, mid-cycle or luteal. Women in the luteal phase were significantly less controlled and more impulsive than women earlier in their cycle. A significant correlation was also found for over-spending, lack of control and buyer's remorse with day of cycle. These findings suggest that the adverse impact of ovarian hormones upon self-regulation may account for impulsive and excessive economic behaviour in women.
\end{abstract}

Key words: women spending impulsivity self-regulation hormones 


\section{Women's Spending Behaviour is Menstrual-Cycle Sensitive}

Economic behaviour and consumer decisions are not always rational and the illogical processes that can hijack them are becoming better understood. Expected utility theory (see Tversky and Kahneman, 1981), that individuals make logical decisions and are driven to amass as much money as possible, has been questioned by cognitive psychologists. The work of Kahneman in particular drew attention to people's over-reliance on heuristics and hunches and under-use of logic when making economic decisions in the face of uncertainty (Kahneman and Tversky, 1979; Kahneman, Slovic, and Tversky, 1982). In addition to cognitive biases, affective factors also play a significant role in people deviating from economically normative behaviour. The emotions implicated in unrestrained behaviour give rise to impulse buying, compulsive spending and inability to exercise financial self-control (Faber \& Christensen, 1996; Verplanken \& Herabadi, 2001). This can lead to money pathologies and a range of neuroses associated with money (Goldberg and Lewis, 1978; Mitchell and Mickel, 1999).

Research has also shown that money is a more emotionally loaded topic for women than for men (Gresham and Fontenot, 1989). Females have been found to be more extravagant than men but also more anxious about money (Rubinstein (1981) and more prone to depression and compulsive spending (Furnham and Okamura, 1999). They also feel a greater sense of envy for money and deprivation when faced with a lack of it (Prince, 1993). In addition, women's self of sense is more closely tied to shopping than men's and women attach more significance to the shopping experience than men (Dittmar and Drury, 2000). They regard it as more complimentary to their role (Kelly, 1991) and are more inclined to engage in behaviours such as dressing up to go shopping (Johnstone and Conroy, 2005). 
A number of explanations can be advanced to explain women's propensity towards money pathologies, but, one potential biological factor has not been considered. That is the influence of the female menstrual cycle on their financial behaviour. The phases of the menstrual cycle have a vast range of behavioural, psychological and physical correlates although to date their implication in female economic behaviour has been largely ignored. There is related behavioural research that suggests there might be effects. It is well documented, for example, that women are more rational and controlled post-ovulation, but experience a rise in impulsive behaviour, anxiety and irritability during the pre-menstrual (or luteal) phase (Baca-Garcia, 2000; Van Goozen, Weigant, Endert, \& Helmond, 1997). At ovulation, or peak fertility, it has been shown that women adapt their dress style to impress men - known as the ornamentation effect (Hazelton et al. 2007). At this time women are also twice as likely to engage in extra-marital behaviour, with commitment to relationships peaking mid-cycle when progesterone is high (Jones et al. 2005). Changes with menstrual phases have also been reported in women's emotion recognition accuracy (Derntl et al. 2008), preferences for masculinity in male bodies (Little, Jones and Burriss, 2007), fear recognition (Pearson and Lewis, 2005), turning bias (Mead and Hampson, 1997), mood and food cravings (Cohen, Sherwin, and Fleming, 1987). Females are also twice as likely to succeed at smoking cessation in the luteal phase of their cycle (Allen et al. 2008) but more likely to injure themselves during exercise (Moller-Nielsen \& Hammar, 1989) It therefore seems implausible to assume that women's behaviour with money will not be affected by the fluctuations of endogenous estrogen capable of producing such varieties of responses. Although money arrived relatively late on the evolutionary stage and is unlikely to have a brain mechanism directly associated with it (for a discussion of this see Burgoigne \& Lea, 2006) the neurons in the orbitofrontal cortex that encode food selection have also been found to encode economic value (Padoa-Schioppa \& Assad, 2006) thus suggesting shared neural 
substrates. One could speculate that female spending behaviour has its evolutionary roots in early foraging expeditions. Cyclic shifts in spending may have arisen from pressure to forage more after the reduction in food consumption that accompanies ovulation (Fessler, 2003) and before the onset of menses. Women also experience cyclic changes in mood, with negative affect rising during the luteal phase (Van Goozen et al, 1997), so fluctuations in economic behaviour may be motivated by the need to regulate emotions (Gross, 2002).

Furthermore, there is now compelling evidence from functional magnetic resonance imaging studies for fluctuations in activity in the orbitofrontal cortex (OFC) region of the brain during the menstrual cycle (Protopopescu et al. 2005). The OFC is involved in motivational operations, especially the alteration of stimulus-reward associations, inhibitory control and emotional regulation. More importantly, Breiter et al. (2001) found that the OFC is activated by monetary rewards. These developments provide further support for the view that women's ability to maintain a consistent emotional response to monetary stimuli may fluctuate across the cycle.

Female economic behaviour is therefore highly likely to be menstrual-cycle sensitive. The research presented here investigates this hypothesis. Over 700 pre-menopausal women were recruited to complete a questionnaire about their relationship with money. The women answered a series of questions about the emotions that were likely to impact upon their spending behaviour. A section also asked the women about their spending in the last seven days, with statements aimed at identifying money inappropriate behaviour with money (Furnham and Okamura, 1999) e.g., impulsive buying, overspending and lack of control. Finally, within a set of demographic questions, women were given the option to report the date of their last period. From this it was possible to calculate where the women were in their menstrual cycle. In common with other cycle shift studies, the cycle was divided into the follicular, mid-cycle and luteal phases, and the women's recent spending behaviour was analysed in relation to phase of cycle. Since changes in 
OFC activity across the menstrual cycle affect inhibitory control this may be reflected in an increase in impulse buying, which is defined as involving 'spontaneous and unreflective desire to buy, without thoughtful consideration of why and for what reason a person should have the product' (Vohs and Faber, 2007, 537). In an experimental study that lowered participants' selfregulatory resources Vohs and Faber (2007) found that people were less likely to resist the temptation to impulse buy, were willing to spend more and did in fact spend more money in unanticipated purchasing situations. Therefore our Recent Spending and Saving Scale included statements about impulsive, uncontrolled and excessive spending. Statements also asked about positive behaviours (such as keeping to a budget and putting money into savings) and affect (such as worry or guilt after spending). We predicted that women in the luteal phase would report heightened impulsivity in the spending behaviour and more irrational and uncontrolled spending.

\section{METHOD}

\section{Participants}

Participants were recruited through an editorial piece in a popular monthly women's magazine. The item stated that psychologists at the University of Hertfordshire were conducting research into women's relationship with money and invited women, aged $18-50$, to complete an anonymous on-line survey.

Seven hundred and three women took part in the survey. Towards the end of the survey they answered demographic questions and were given an option of providing information about the date of their last period and whether they were currently prescribed oral contraception. Four hundred and forty three women completed this section. 
Age. The 443 women were classified into four age groups: 18-24 years old $(\mathrm{n}=83), 25-34$ years old $(n=162), 35-44$ years old $(n=148)$ and $45-50$ years old $(n=50)$. Thus, $70 \%$ of the sample was aged between 25 and 44 years old.

Marital status. Three hundred and nine (70\%) of the women were married, co-habiting or in relationship; the remaining $30 \%$ were single.

Background. Thirteen of the women (3\%) were unemployed, 67 (15\%) were studying, 29 (6\%) were at home with children, $106(24 \%)$ had administrative or managerial roles, $168(38 \%)$ were professional women and $60(13.5 \%)$ were self-employed. Therefore over $75 \%$ of the women were earning an income.

Income. Participants reported annual household income. For 82 of the women (18.5\%) this was below $£ 20,000$, for 145 (32.7\%) from $£ 21,000$ to $£ 40,000$, and the same number (145) were in the $£ 41,000$ to $£ 75,000$ income bracket; 71 (16\%) women reported income greater than $£ 75,000$. Oral Contraception. Just over a quarter of the women (121) were taking the oral contraceptive pill. Three hundred and ninety-seven (90\%) of women reported regular periods (28+/- 5 days).

Materials

Fifteen statements were devised to describe women's use of money in the seven days prior to completing the survey, including inappropriate money behaviours (Furnham and Okamura, 1999), such as impulse buying, lack of control and self-regulation. A five-point Likert response scale accompanied each statement with response options Strongly Agree, Agree, Neither Agree nor Disagree, Disagree, Strongly Disagree.

An exploratory factor analysis using the maximum likelihood method was conducted on the 15 items of the Recent Spending and Saving Scale (RSSS) to measure the dimensionality of the 
scale. A single factor emerged and accounted for $42 \%$ of the variance. The reliability of the scale was high, with a Cronbach $\alpha=.892$ for 15 items $(n=443)$. No items were removed.

\section{RESULTS}

Details of their menstrual cycle (i.e. length of cycle and date of last menses) were provided by 443 women and, of these, $121(27 \%)$ indicated they were taking the contraceptive pill. Pharmacological suppression of ovarian hormones renders pill-users less susceptible to the fluctuations of the menstrual cycle therefore only data for normal cycling women $(n=322)$ were analysed.

From the date of their last menses to the date they completed the survey it was possible to categorise where the normally cycling women were in their cycle. As table 1 shows, $34 \%$ were in the follicular phase, $18 \%$ were mid-cycle and $48 \%$ were in the luteal phase.

Insert table 1 about here

Scores on the Recent Spending and Saving Scale across menstrual phases

Mean scores for the Recent Spending and Saving Scale (RSSS: for spending behaviour in the previous seven days) were calculated by phase. Higher scores indicate less control over spending in the past seven days, with a maximum of 75 and a minimum possible score of 15 . Scores ranged from 16 to 72 (mode 40), with scores increasing across the menstrual phases. As table 2 shows, mean RSSS scores for women in the follicular phase were lowest, $M=39.83$, (SD 
= 11.49), higher for women in the mid-cycle phase $M=42.80,(\mathrm{SD}=12.68)$, and highest for those in the luteal phase $M=43.44,(\mathrm{SD}=11.42)$

Insert table 2 about here

A one-way analysis of variance (ANOVA) found a significant difference between the mean scores according to phase, $F(2,319)=3.19, p=.043$. Follow-up pair-wise analyses using the LSD method indicated that mean scores for women in Phase 3 (the luteal phase) were significantly higher than those for women in Phase 1 (the follicular phase), $p=.014$.

\subsection{Correlations between scores on each statement and day of cycle}

The RSSS scores suggest that self-regulation of spending decreases through the menstrual cycle. To explore this further correlations using the Pearson correlation coefficient were calculated for the day of cycle with mean score for each statement on the RSSS (see table 3).

Insert table 3 about here

As table 3 indicates, low but significant positive correlations were found for nine of the fifteen statements. As the day of cycle increased so did agreement with items that related to excessive spending, unplanned or impulsive spending. There were also fewer positive spending behaviours later on in the cycle. ANOVAs on the mean scores for each of these statements by phase showed no suggestion of approaching significance $(F(2,319)=0.115$ and $1.825 ; p>0.1)$. A Principal Components Analysis of the 15 RSSS items (which looks at total variance, as opposed 
to the common or shared variance of EFA) did show these two items formed a separate 'negative affect factor'. The mean score based on these two items also showed no difference across phases either $(\mathrm{F}(2,319)=0.994, \mathrm{p}=.371)$.

\section{DISCUSSION}

The aim of this study was to establish whether fluctuations in ovarian hormones, which account for variations in a wide range of female cognitive and affective responses, influence women's behaviour with money. To our knowledge, this is the first study to show that women's behaviour with money is menstrual-cycle sensitive.

From the questionnaire a strong factor emerged that related to impulsive spending and significant differences across menstrual phase. Spending was less controlled, more impulsive and more excessive for women in the luteal phase, or the further on they were in their cycle, compared to the earlier, follicular phase. There are wide reports of psychological and physical symptoms that affect women during the luteal phase and then remit by the follicular phase, with the overwhelming majority of premenopausal women experiencing these symptoms to some degree (Collins Reed, Levin, and Evans, 2008). Women report mood swings at this time, increased irritability and impulsivity, as well as impaired memory, concentration and motor coordination. It is therefore unsurprising that women in this study who were in the luteal phase reported some dysfunctional behaviour with money. This manifested in them feeling out of control, spending more money than they had intended to and a greater incidence of unplanned spending or purchasing of items on impulse (almost two-thirds of the women had bought something on impulse). Although Wood (2005) has proposed revising the concept of unplanned spending, claiming that it can be discretionary and forms part of the core meaning of a 'consumer 
society', data from the study reported here suggest that impulse purchases can be costly (in fact, $57 \%$ had spent more than $£ 25$ than they needed to; $6 \%$ had spent more than $£ 250$ more) and have emotional consequences, since in $28 \%^{1}$ of cases buyers were left with feeling of remorse.

Rook and Fisher (1995) drew attention to a relationship between both trait and normative aspects of impulse buying. They suggest that individuals may be predisposed to impulse buy but their normative judgments will mediate this tendency and influence buying decisions. In this study we did not take trait measures of impulse buying, although future studies could ascertain how this interacts with menstrual cycle phase. Our prediction is that women with high trait impulse-buying tendencies would show greater depletion of control during the luteal phase and the effects found here would be magnified in impulsive respondents. We would concur with Vohs and Faber (2007) who conceptualize impulse buying as a depletion of the resource that governs self-control; an influence that is more state than trait. They demonstrated that when participants' self-regulatory resources (including cognitive strategies, such as lowering one's own valuation of the desired purchase) were depleted they were more likely to be tempted to make unplanned purchases and to spend more money, a response known as behavioural rebound (Erskine, 2007). Support for this state-induced resource-depletion explanation comes from findings that the amount people are willing to spend varies according to physiological states, such as hunger (Briers et al. 2006), and affective states, such as depression (Cryder et al. 2008). We suggest that, in common with other cognitive competencies, the resources that govern spending may also be menstrual-cycle sensitive and our data reflect women's lower self-regulatory resources during the luteal phase.

\footnotetext{
${ }^{1}$ Percentages based on the number of participants who responded agree or strongly agree to the item on the RSSS
} 
We believe these data are compelling, despite some methodological limitations. The data were collected via an on-line survey, which can sometimes yield duplicate or junk responses. A check of the IP addresses for each respondent found no duplicates, and many women left free text comments, which lead us to believe these were authentic responses. The participants responded to a call for volunteers through a popular national women's magazine. The sample was therefore self-selecting and no doubt the survey appealed to women who were interested in their relationship with money. The call for participants did not mention hormonal influences on spending, however, and care was taken to ensure that the survey introduction did not allude to the effect of hormones on spending. Self-report of last menses is a convention followed in other cycle shift studies that has high reliability when validated against physiological measures (e.g. Jones, Little, et al. 2005; Stricker et al. 2006). Questions about recent spending preceded those about the date of the last menses. Therefore it is unlikely that women were primed to view their spending in the last seven days as less controlled than it was and the lack of correlation between cycle phase and affective responses also suggests this may not be an issue. The two items in the RSSS which appear to relate more to negative affect ("I have felt shame or guilt after a shopping trip" and 'I have worried about money") did not show any significant correlations with day of cycle. This suggests that women in the luteal phase were not simply retrieving mood-congruent memories when in fact objectively they were not more impulsive.

Therefore, whilst self-report data have to be treated with some caution, this study benefits from being conducted with a large sample using a scale with high internal validity. We recommend that greater consideration be given to phase of menstrual cycle when analyzing female spending behaviour in future. Furthermore, women may benefit from being aware that there are times when their self-regulatory resources are compromised and they could time spending decisions and consumer behaviour accordingly. 


\section{REFERENCES}

Allen, S. S., Bade T., Center B., Finstad D., and Hastsukami D. (2008). Menstrual phase effects on smoking relapse. Addiction,103, 809-21.

Baca-García, E., Díaz-Sastre, C., de Leon, J., and Saiz-Ruiz, J. (2000).

The relationship between menstrual cycle phases and suicide attempts. Psychosomatic Medicine, $62,50-60$.

Briers, B., Pandalaere, M., Dewitte, S., and Warlop, L. (2006). Hungry for money: The desire for calorie resources increases the desire for financial resources and vice versa. Psychological Science, 17, 11, 939-43.

Breiter, H., Aharon, I., Kahneman, D., Dale, A., and Shizgal, P. (2001).

Functional imaging of neural responses to expectancy and experience of monetary gains and losses. Neuron, 30, 2, 619-39.

Burgoyne, C., and Lea, S.E.G. (2006). Money is material. Science, 314, 1091-1092.

Cohen, I., Sherwin, B., and Fleming, A. (1987). Food cravings, mood and the menstrual cycle. Hormones and Behaviour, 21, 44, 457-70.

Collins Reed, S., Levin, F., and Evans, S. M. (2008). Changes in mood, cognitive performance and appetite in the late luteal and follicular phases of the menstrual cycle in women with and without PMDD. Hormones and Behaviour, 54, 1, 185-93.

Cryder, C.E., Lerner, J.S., Gross, J. J., and Dahl, R. E. (2008). Misery is not miserly. Sad and self-focused individuals spend more. Psychological Science, 19, 6, 525-30.

Derntl, B., Kryspin-Exner, I., Fernbach, E., Moser, E., and Habel, U. (2008). Emotion recognition accuracy in healthy young females is associated with cycle phase. Hormones and Behaviour, 53, 1, 90-5. 
Dittmar, H. and Drury, J., (2000). Self-image. Is it in the bag? A qualitative comparison between ordinary and excessive consumers. Journal of Economic Psychology, 21, 2, 109-42.

Elliott, R. (1994). Addictive consumption: Function and fragmentation in post-modernity. Journal of Consumer Policy, 17, 2, 159-79.

Erskine, J. A. K. (2007). Resistance can be futile: Investigating behavioural rebound. Appetite, 50, 415-21.

Faber, R.J., and Christensen, G.A. (1996). In the mood to buy: Differences in the mood states experienced by compulsive buyers and other consumers. Psychology \& Marketing, 13 (8), 803-819.

Furnham, A. and Okamura, R. (1999). Your money or your life: behavioural and emotional predictors of money pathology. Human Relations, 52, 9, 1157-77.

Goldberg, H. and Lewis, R., (1978). Money madness: The psychology of saving, spending, loving and hating. London: Springwood.

Gresham, A. and Fontenot, G. (1989). The different attitudes of the sexes towards money: An application of the money attitude scale. Advances in Marketing. 8, 380-84.

Gross, J. J., (2002). Emotion regulation: Affective, cognitive, and social consequences. Psychophysiology, 39, 281-291.

Hazelton, M., Mortazele, M., Pillsworth, E., Bleske-Rechek, A..,and Frederick, D. (2007). Ovulatory shifts in human female ornamentation: Near ovulation, women dress to impress. Hormones and Behaviour, 51, 1, 40-5.

Howard, R., Gifford, M.,and Lumsden, J. (1988) Changes in an electrocortical measure of impulsivity during the menstrual cycle. Personality and Individual Differences Volume 9, Issue 5, $917-918$ 
Johnstone, M., and Conroy, D.,(2005). Dressing for the thrill - women dress up to go shopping. Journal of Consumer Research, 4, 4, 234-54.

Jones, B., Little, A. C., Boothroyd, L., DeBruine, L. N., Feinberg, D. R., Law Smith, M. J., Cornwell, R. E., Moore, F., and Perrett, D. (2005). Commitment to relationships and preferences for femininity and apparent health in faces are strongest on days of the menstrual cycle when progesterone level is high. Hormones and Behaviour, 48, 3, 283-90.

Kahneman, D. and Tversky, A. (1979). Prospect theory: An analysis of decision under risk. Econometrica, 47, 263-91.

Kahneman, D., Slovic, P., and Tversky, A. ed. (1982). Judgment under uncertainty: Heuristics and biases. New York: Cambridge University Press.

Kelly, J. (1991). Commodification and consciousness: an initial study. Leisure Studies, 10, 7-18.

Little, A.C., Jones, B. C., and Burriss, R. P. (2007). Preferences for masculinity in male bodies change across the menstrual cycle. Hormones and Behaviour, 51, 5, 633-39.

Mead, L. and Hampson, E. (1997). Turning bias in humans is influenced by phase of the menstrual cycle. Hormones and Behaviour, 31, 1, 65-74.

Mitchell T. and Mickel, A. E. (1999). The meaning of money: An individual-difference perspective. Academy of Management Review, 24, 3, 568-78.

Moller-Nielsen, J. and M. Hammar (1989). Women's soccer injuries in relation to the menstrual cycle and oral contraceptive use. Medicine and Science in Sports and Exercise, 21, 2, 126-129,

Nyhus, E. and Webley, P. (2001). The role of personality in household saving and borrowing behaviour. European Journal of Personality, 15, 88-103. 
Padoa-Schioppa, C., and Assad, J.A. (2006). Neurons in the orbitofrontal cortex encode economic value. Nature, 441, 223-226

Pearson, R. and Lewis, M. B., (2005). Fear recognition across the menstrual cycle. Hormones and Behaviour, 47, 267-71.

Prince, M., (1993). Women, men and money styles. Journal of Economic Psychology, 14, $1,175-82$.

Protopopescu, X., Hong Pan, Altemus, M., Tuescher, O., Polanecsky, M., McEwen, B., Silbersweig, D., and Stern, E. (2005). Orbitofrontal cortex activity related to emotional processing changes across the menstrual cycle. Proceedings of the National Academy of Sciences, November 1, 102, 44, 16060-65.

Rook, D. W. and Fisher, R. J., (1995). Normative influences on impulsive buying. Journal of Consumer Research, 22, 305-13.

Rubenstein, C. (1981). Survey report on money. Psychology Today, 5, 24-44.

Stricker, R., Eberhart, R., Chevailler, M.C., Quinn, F.A., Bischof P., and Stricker, R. (2006). Establishment of detailed reference values for luteinizing hormone, follicle stimulating hormone, estradiol, and progesterone during different phases of the menstrual cycle on the Abbott ARCHITECT $^{\circledR}$ analyzer. Clinical Chemistry and Laboratory Medicine, 44, 883-87.

Tversky, A. and Kahneman, D. (1981). The framing of decisions and the psychology of choice. Science, 211, 453-58

Van Goozen, S., Weigant, V.M., Endert, E., and Helmond, F.A.(1997).

Psychoendocrinological assessment of the menstrual cycle: the relationship between hormones, sexuality and mood. Archives of Sexual Behaviour, 26, 359-382.

Verplanken, B., \& Herabadi, A. (2001). Individual differences in impulse buying tendency: Feeling and no thinking. European Journal of Personality, 15, S71-S83. 
Vohs, K. D. and Faber, R. J. (2007). Spent resources: Self-regulatory resource availability affects impulse buying. Journal of Consumer Research, 33, 537-47.

Wood, M. (2005). Discretionary unplanned buying in consumer society. Journal of Consumer Behaviour, 4, 4, 268-81. 


\section{Acknowledgements}

The authors are grateful to all the women who participated in the study. Also to Dr. Avril Nash, Jessica Chivers and Simonne Gnessen for their help with data collection and analysis. 
Table 1: Categories of menstrual phase and number of women in each phase.

\begin{tabular}{|l|l|c|}
\hline Phase & Days & n \\
\hline $\begin{array}{l}\text { Follicular } \\
\text { (menstrual and post-menstrual) }\end{array}$ & $1-11$ & 110 \\
\hline $\begin{array}{l}\text { Mid-cycle } \\
\text { (ovulatory) }\end{array}$ & $12-16$ & 59 \\
\hline $\begin{array}{l}\text { Luteal } \\
\text { (pre-menstrual) }\end{array}$ & $17-28+$ & 153 \\
\hline
\end{tabular}


Table 2: Mean scores on RSSS for women in each menstrual phase

\begin{tabular}{|l|c|c|}
\hline Phase & Mean RSSS score & SD \\
\hline Follicular $(\mathrm{n}=110)$ & 39.83 & 11.49 \\
\hline Mid-cycle $(\mathrm{n}=59)$ & 42.80 & 12.68 \\
\hline Luteal $(\mathrm{n}=153)$ & 43.44 & 11.42 \\
\hline
\end{tabular}


Table 3: Pearson correlation coefficients between day of cycle and mean score on Recent Spending and Saving scale items.

\begin{tabular}{|c|c|c|}
\hline Statement & $r$ value & $p$ \\
\hline Overall RSSS mean Score & .17 & .003 \\
\hline $\begin{array}{l}\text { In the last } 7 \text { days I have spent } £ 25 \text { or more than I } \\
\text { needed to. }\end{array}$ & .20 & .000 \\
\hline My spending has been out of control & .16 & .005 \\
\hline $\begin{array}{l}\text { In the last } 7 \text { days I have spent } £ 250 \text { or more than I } \\
\text { needed to. }\end{array}$ & .14 & .012 \\
\hline $\begin{array}{l}\text { I have bought something I wouldn't normally buy } \\
\text { because it was on special offer }\end{array}$ & .13 & .016 \\
\hline I have regretted buying something & .13 & .02 \\
\hline I have spent more than I could afford & .12 & .033 \\
\hline $\begin{array}{l}\text { I have gone shopping for something and come home } \\
\text { with something completely different }\end{array}$ & .11 & .04 \\
\hline $\begin{array}{l}\text { In the last } 7 \text { days I have spent } £ 100 \text { or more than I } \\
\text { needed to. }\end{array}$ & .11 & .053 \\
\hline I have bought something on impulse & .10 & .07 \\
\hline $\begin{array}{l}\text { I have bought something that I am unlikely to } \\
\text { wear/use }\end{array}$ & .08 & .15 \\
\hline I have felt shame or guilt after a shopping trip. & .09 & .10 \\
\hline I have worried about money. & .004 & .95 \\
\hline$\dagger$ I have set myself a budget and stuck to it. & .14 & .012 \\
\hline$\dagger$ My spending has been careful and controlled. & .12 & .032 \\
\hline$\dagger$ I have put some money in savings. & -.03 & .62 \\
\hline
\end{tabular}

